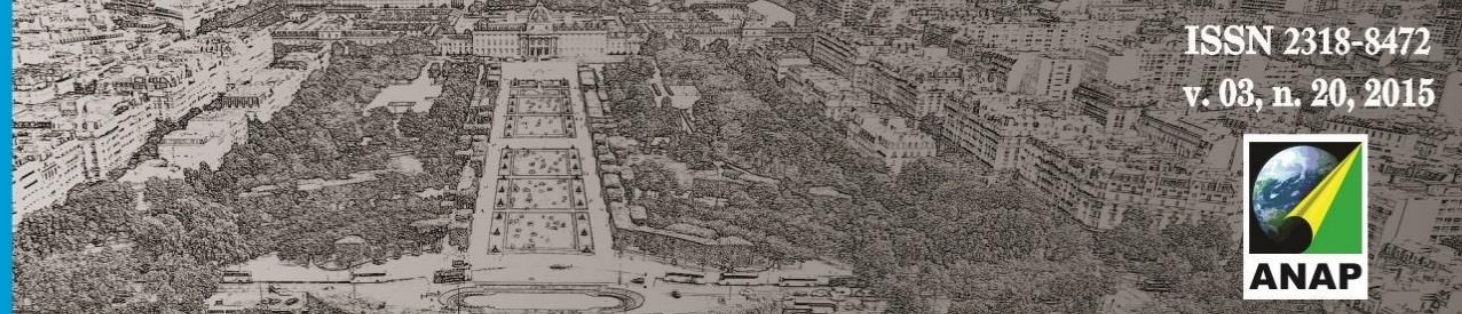

Revista Nacional de

Gerenciamento de Cidades

\title{
A ACESSIBILIDADE ESPACIAL COMO INCLUSÃO DE ALUNOS EM ESCOLA DE EDUCAÇÃO INFANTIL
}

\author{
Edmilson Queiroz Dias ${ }^{1}$
}

Renata Cardoso Magagnin ${ }^{2}$

\begin{abstract}
RESUMO
Este artigo tem como objetivo verificar o grau de inclusão escolar nos edifícios escolares de ensino infantil do município de Bauru, para alunos com deficiência motora. O estudo de caso foi realizado em uma escola de ensino infantil, localizada no município de Bauru, Estado de São Paulo, Brasil. Para esta análise foram utilizados os seguintes métodos: análise da acessibilidade espacial nas edificações através da utilização da técnica de vistoria técnica através da utilização de checklist, análise da acessibilidade espacial através leitura da planta humanizada e registro fotográfico. Os resultados obtidos nesta pesquisa conduziram às seguintes conclusões: i) as escolas municipais de ensino infantil estão recebendo alunos deficientes (físico, visual, intelectual, etc.), no entanto, nem todos os espaços foram projetados ou adaptados para receber estes alunos; em alguns casos, estas adaptações não contribuem para a efetiva inclusão escolar destes alunos; e ii) a partir dos problemas elencados nesta pesquisa, o município pode formular e implantar ações a curto, médio e longo prazos para tornar as escolas infantis acessíveis e mais includentes.
\end{abstract}

PALAVRAS-CHAVE: Acessibilidade Espacial. Inclusão Escolar. Escola Infantil.

\section{ACCESSIBILITY SPACE AS INCLUSION OF STUDENTS IN SCHOOL EARLY CHILDHOOD EDUCATION}

\begin{abstract}
ABSTRAC
This paper aims to verify, at the school of inclusion, the degree of accessibility of students with disabilities in buildings of children's education in the city of Bauru. The case study was performed in a children's school, located in the city of Bauru, State of São Paulo, Brazil. For this analysis of accessibility in buildings, the following methods were used: technical inspection with checklist, reading the humanized plant and photographic record. The results obtained in this study led to the following conclusions: i) municipal children's education schools have been receiving disabled students (physical,

\footnotetext{
${ }^{1}$ Pós-graduando em Arquitetura e Urbanismo, UNESP - Universidade Estadual Paulista, Faculdade de Arquitetura, Artes e Comunicação, Bauru - SP. edmilsonqueirozdias@gmail.com

${ }^{2}$ Professora Assistente Doutora, UNESP - Universidade Estadual Paulista, Faculdade de Arquitetura, Artes e Comunicação, Bauru - SP. magagnin@faac.unesp.br
} 
Revista Nacional de

Gerenciamento de Cidades

visual, intellectual, etc.), however, not all spaces have been designed or adapted to receive these students; in some cases, these adaptations do not contribute to the effective school inclusion of these students; and ii) from the listed problems in this research, the municipality can formulate and implement actions in the short, medium and long term to make children's schools more accessible and more inclusive.

KEYWORDS: Spatial Accessibility. Inclusive Education. Children School.

\title{
ESPACIO ACCESIBILIDAD COMO LA INCLUSIÓN DE LOS ESTUDIANTES EN LA ESCUELA EDUCACIÓN INFANTIL
}

\begin{abstract}
RESUMME
Este artículo tiene como objetivo determinar el nivel de escolarización en los edificios escolares de jardín de infantes en la ciudad de Bauru, para estudiantes con discapacidades físicas. El estudio de caso se llevó a cabo en una escuela de la guardería, ubicada en la ciudad de Bauru, Sao Paulo, Brasil. Para este análisis, se utilizaron los siguientes métodos: análisis de la accesibilidad espacial de los edificios a través de la utilización de la técnica de inspección técnica usando lista de verificación, el análisis de la accesibilidad espacial a través de la lectura y humanizado planta de registro fotográfico. Los resultados de esta investigación llevó a las siguientes conclusiones: i) las escuelas públicas de kindergarten están recibiendo los estudiantes con discapacidad (física, visual, intelectual, etc.), sin embargo, no todos los espacios están diseñados o adaptados para recibir a estos estudiantes; en algunos casos, estas adaptaciones no contribuyen a la inclusión escolar efectiva de estos estudiantes; y ii) a partir de los problemas enumerados en esta investigación, el municipio puede formular e implementar acciones en el corto, mediano y largo plazo para que las guarderías accesibles y más inclusiva.
\end{abstract}

PALABRAS CLAVE: Inclusión Escolar. Política Pública. La accesibilidad espacial.

\section{INTRODUÇÃO}

As escolas de educação infantil devem propiciar condições para que as crianças possam desenvolver plenamente suas potencialidades, respeitando a diferença de todos. Para que isto ocorra, os ambientes não podem ser um limitador, ou seja, deve permitir o livre acesso de todos independente de sua restrição, seja ela física/motora, visual ou intelectual (Elali, 2002; Corrêa, 2010).

Um edifício de educação infantil deve integrar os diferentes espaços. Cada ambiente deve ser dimensionado de acordo com cada atividade proposta. É necessário levar em consideração o conforto dos usuários, a acessibilidade, os fluxos, a ergonomia, entre outros aspectos (França, 2011). O espaço físico da escola tem um impacto direto e simbólico sobre este aluno, pois pode ser um facilitador ou inibidor de 


\section{Revista Nacional de}

Gerenciamento de Cidades

seu comportamento (Elali, 2002).

A organização espacial de uma escola de educação infantil permite identificar como ocorre a interação entre os indivíduos e entre eles e os ambientes; este diagnóstico pode ser realizado através da análise do fluxo e das formas de circulação, bem como da proximidade entre os espaços de salas de atividades, áreas de recreação, vivência, assistência e serviços, que podem favorecer ou não as relações intra e interpessoais (Brasil, 2006). Um ambiente acessível deve proporcionar facilidades no deslocamento, uso, comunicação e orientação espacial. Estes quatro fatores são interligados, o não cumprimento de um deles compromete no desempenho dos demais elementos.

A concepção de um espaço funcional e operacional, comprometido com a acessibilidade, contribui para o processo de aprendizagem dos alunos. De acordo com Dischinger; Bins Ely; Borges (2009) para o ambiente escolar ser inclusivo, os espaços devem possibilitar não apenas o acesso físico, mas permitir que todas as crianças possam participar de todas as atividades.

Um ambiente escolar inadequado, com barreiras arquitetônicas, pode comprometer o desenvolvimento cognitivo da criança com deficiência e assim comprometer a educação inclusiva ${ }^{3}$ em escolas de ensino regular (Benvegnú, 2009). Estas barreiras podem constituir-se em obstáculos para o ensino de alunos com deficiência física, visual e com mobilidade reduzida. Elas impedem que estes alunos possam ter uma mesma oportunidade de participar em igualdade de condições das atividades no espaço físico, podendo ficar isolados física e socialmente (Corrêa, 2010; Loch, 2007; Benvegnú, 2009).

A partir destas definições, este artigo apresenta uma proposta para avaliação do grau de inclusão escolar a partir da acessibilidade espacial nos edifícios escolares de ensino infantil, para alunos com deficiência física (motora). O estudo de caso foi realizado na EMEI Lions Club localizada em Bauru (Estado de São Paulo, Brasil).

\footnotetext{
${ }^{3}$ O conceito de inclusão escolar está definido na Lei Federal 12.796/2013, que estabelece a Lei de Diretrizes e Bases da Educação Nacional (LDB). Nela a inclusão está associada ao conceito de escola inclusiva e educação inclusiva, ou seja, tanto o edifício quanto a proposta pedagógica devem oferecer a inserção de todos os alunos na escola (Abate, 2011; Evangelista, 2007; Brasil, 2013).
} 


\section{METODOLOGIA}

Para verificar o grau de inclusão escolar, através da acessibilidade espacial, nos edifícios escolares de ensino infantil do município de Bauru foram utilizados os seguintes procedimentos metodológicos: vistoria técnica através da utilização do checklist, leitura da planta humanizada e registro fotográfico.

\section{- Vistoria Técnica ou Método do Checklist}

A primeira etapa consistiu na definição forma de realização de uma vistoria técnica dos ambientes internos e externos da escola analisada. Inicialmente foram definidos os elementos ou variáveis que poderiam comprometer a acessibilidade espacial em uma escola de ensino infantil. Para esta definição foram utilizados como referência os seguintes documentos: a Norma Técnica de Acessibilidade - NBR 9050, o Decreto Federal 5296/2004, os Protocolos de Acessibilidade Escolar desenvolvidos por: Dischinger; Bins Ely; Borges (2009); Carvalho (2008); Audi (2004) e Ada (1995). Os ambientes foram agrupados nos seguintes temas: Acesso à Escola, Acesso aos Edifícios, Área Administrativa, Área Pedagógica, Área de Alimentação, Circulação Externa, Parque Infantil I, Parque Infantil II Parque Infantil III e Piscina. Cada ambiente foi subdivido por um elenco de indicadores que permitiu avaliar detalhadamente a acessibilidade espacial da escola.

Os indicadores utilizados foram: Entrada principal (largura, desnível, tipo de piso); Portas (largura, proteção para cadeira de rodas, soleira - desnível, tipo de piso, nivelamento piso); Corredor (largura, tipo de piso, desnível, grelhas coleta de água de chuva - posição e espaçamento das grelhas); Salas da Administração (portas e layout); Sala de Aula (altura da lousa/espelho, altura da mesa, disposição dos mobiliários); Sanitários (altura do lavatório, barras de apoio no lavatório, área do boxe do vaso sanitário, área de transferência do vaso sanitário, elevação do vaso sanitário, barra de apoio no vaso sanitário, área do boxe do chuveiro, barra de apoio na área do chuveiro, área transferência do trocador, barra de apoio no trocador); Refeitório (altura 
Revista Nacional de

Gerenciamento de Cidades

da mesa, altura do bebedouro, altura do controle para acionar água do bebedouro, barra de apoio no bebedouro, altura da base do bebedouro); Parque Infantil (tipo de piso, existência de rota acessível, segurança dos brinquedos, distância entre os brinquedos, balanços para crianças de até três anos, manutenção do piso - areia); Piscina (acesso, banco de transferência, profundidade); Rampa (largura, inclinação, corrimão); Escada (profundidade do degrau, altura do espelho, corrimão).

Os indicadores foram avaliados através de dois parâmetros: ambiente acessível (atende 100\% das recomendações da NBR 9050) e ambiente não acessível (não atende as diretrizes da norma técnica de acessibilidade). Após esta avaliação individual foi definido o grau de acessibilidade de escola, a partir da avaliação dos agrupamentos dos ambientes escolares por Temas. Para um ambiente (Tema) ser considerado acessível, convencionou-se, neste estudo, que a avaliação deveria ser superior a $75 \%$.

Posteriormente, foi realizada a análise da planta humanizada da escola. Nesta análise foi realizado um estudo sobre o deslocamento dos usuários que utilizam cadeira de rodas, nos espaços internos e externos da escola. O objetivo desta etapa foi verificar se os usuários de cadeiras de rodas têm algum problema em utilizar qualquer ambiente da escola, seja em função da disposição espaços (advindos do projeto/construção), seja em função do layout dos mobiliários presentes nos ambientes internos e externos da escola. Para esta análise foi utilizado como referência o estudo desenvolvido por Pereira (2007) e a NBR 9050 (2004).

A análise compreendeu da avaliação largura disponível para o deslocamento linear de um usuário de cadeira de rodas e na sequência foi verificada a possibilidade de realizar um movimento ou deslocamento nos ambientes através da realização de um giro ou manobra da cadeira de rodas de $360^{\circ}$. Para este estudo foi utilizado os seguintes parâmetros: para a faixa de deslocamento linear foi adotada a largura mínima de 0,90m e para a avaliação da área de giro ou manobra da cadeira de rodas foi adotado um diâmetro de 1,50m (Figuras 1a, b, c, d). 

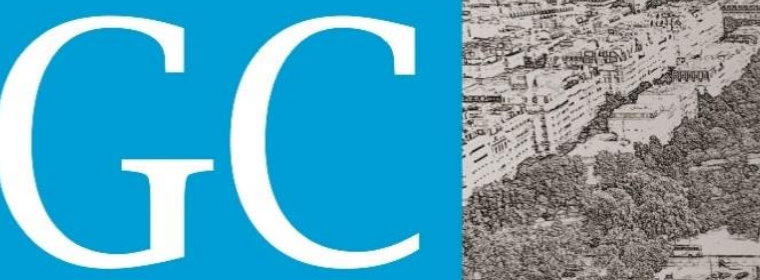

\section{Revista Nacional de}

Gerenciamento de Cidades

Figura 1a, b, c, d - Faixa de deslocamento (a e b) e área de manobra de $360^{\circ}$ do cadeirante (c,d)
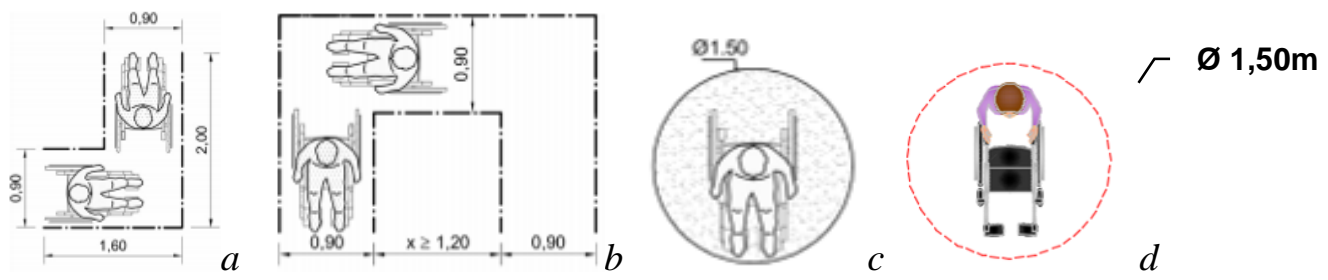

Fonte: ABNT, 2004 e elaborado pelos autores, 2015.

No caso das escolas de ensino infantil os alunos usuários de cadeira de rodas são guiados (conduzidos) por um professor; e embora a cadeira de rodas infantil tenha uma dimensão menor que a cadeira do adulto, em função da necessidade de ser conduzido por um adulto, a área de manobra adotada será a mesma da cadeira de rodas de adulto (ver Figura 1d).

Os registros fotográficos comprovaram os problemas identificados na avaliação por checklist e na análise dos deslocamentos (através da planta humanizada).

\section{- Área de Estudo}

A escola municipal de educação infantil analisada neste artigo foi a EMEI Lions Club. A Escola Infantil está implantada em um terreno de $2.647,25 \mathrm{~m}^{2}$; no bairro Vila Bela Vista, região norte da cidade de Bauru (Figuras 2a e b).

Figuras 2a, b - Localização de Bauru no Estado de São Paulo e localização da escola na quadra e no entorno.
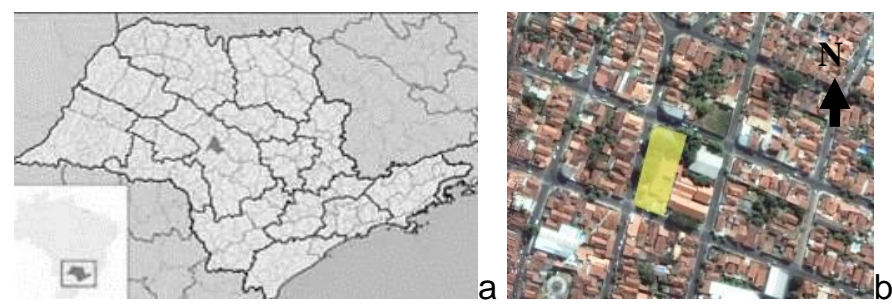

Fonte: Adaptado do Google Earth, 2015.

Atualmente, a escola funciona em período integral, no horário das $7 \mathrm{~h}$ às $17 \mathrm{~h}$. No ano de 2015 estão matriculados 232 alunos, com idade entre 1 ano e 8 meses à 5 


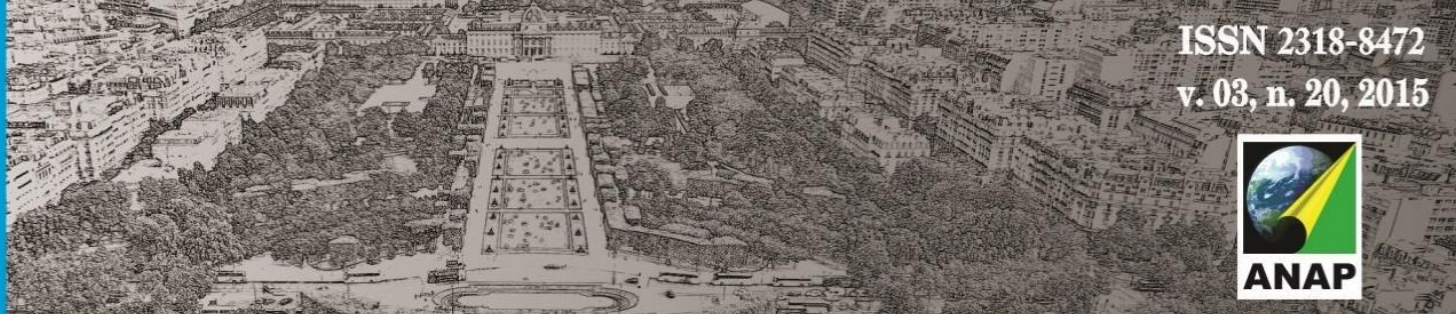

\section{Revista Nacional de}

Gerenciamento de Cidades

anos. Deste total, 05 alunos são portadores de algum tipo de deficiência (paralisia cerebral - 1, hidroencefalia - 1, microcefalia - 1, autista, hemiplagia e sindrômico - 1 de cada, ainda sem laudo médico confirmatório). Trabalham na escola 21 funcionários (diretora, 12 professores, 1 auxiliar, 2 cuidadoras e 5 serventes).

Com relação à divisão de turmas, os alunos estão agrupados em Maternal 1 (crianças com idade entre 1 ano e oito meses a 2 anos), Maternal 2 (alunos com idade de 2 a 3 anos), Jardim 1 (crianças na faixa etária de 3 a 4 anos) e Jardim 2 (alunos com idade de 4 a 5 anos).

A escola possui os seguintes ambientes: sala de direção, secretaria, sala de professores, salas de aulas, berçário, parque infantil, piscina, área verde, cozinha, refeitório, almoxarifado (Figura 3). O edifício principal e as áreas externas (parques infantis) foram construídos no ano de 1957. Em 1968 foram construídas a piscina e o trocador. No ano de 2012, o edifício principal passou por algumas reformas internas e externas, sendo construído um edifício com sanitários e lavanderia.

Figura 3 - Planta da EMEI Lions Club, sem escala.

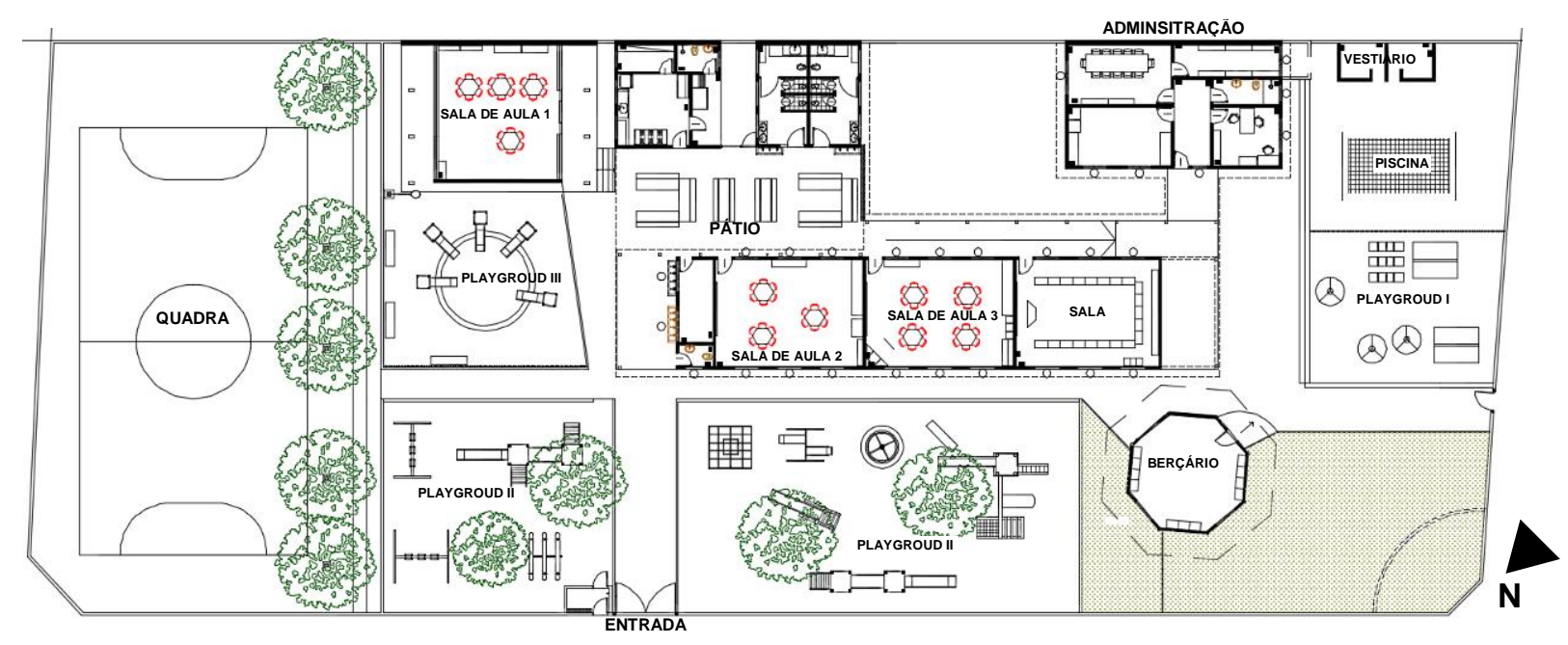

Fonte: adaptado da Prefeitura Municipal de Bauru, 2014.

\section{RESULTADOS E DISCUSSÕES}

A análise dos resultados consistiu na aplicação dos métodos apresentados no 


\section{Revista Nacional de}

Gerenciamento de Cidades

item anterior. Estas análises serão apresentadas na seguinte ordem: i) análise dos ambientes internos e externos da escola através de checklist; e ii) análise da planta humanizada.

\section{- Checklist dos ambientes internos e externo}

A análise da acessibilidade espacial dos ambientes internos e externos da Escola de Ensino Infantil Lions Club foi realizada apenas naqueles ambientes que o aluno, usuário de cadeira de rodas, pudesse ter acesso, ou seja, não foram avaliados os seguintes espaços: sanitários de docentes, lavanderia, cozinha. A Tabela 1 apresenta um resumo da avaliação acessibilidade espacial dos temas e indicadores avaliados na EMEI Lions Club, através da técnica do checklist.

Tabela 1 - Avaliação do grau de acessibilidade espacial da EMEI Lions Club

\begin{tabular}{l|c|c|c|c}
\hline \multirow{2}{*}{\multicolumn{1}{c|}{ Ambiente }} & \multicolumn{4}{c}{ Grau de acessibilidade } \\
\hline & $\mathbf{0 - 2 5 \%}$ & $\mathbf{2 6 \%}$ a $\mathbf{5 0 \%}$ & $\mathbf{5 1 \%}$ a 75\% & $\mathbf{7 6 \%}$ a 100\% \\
\hline Acesso à Escola & & & & $\sqrt{ }$ \\
\hline Acesso aos Edifícios & & & $\sqrt{ }$ & \\
\hline Área Administrativa & & & $\sqrt{ }$ & \\
\hline Área Pedagógica & & & $\sqrt{ }$ & \\
\hline Área de Alimentação & & & $\sqrt{ }$ & \\
\hline Circulação externa & & & & \\
\hline Parque Infantil I & & & & \\
\hline Parque Infantil II & $\sqrt{ }$ & & & \\
\hline Parque Infantil III & $\sqrt{ }$ & & & \\
\hline Piscina & $\sqrt{ }$ & & & \\
\hline
\end{tabular}

Analisando os dados apresentados na Tabela 1, pode-se afirmar que a EMEI Lions Club possui ambientes parcialmente acessíveis aos alunos usuários de cadeiras de rodas. Os espaços identificados com um maior número de problemas de acessibilidade espacial foram: acesso a escola (100\% acessível), acesso aos edifícios (75\% acessível); área administrativa (67\% acessível); área pedagógica (53\% 


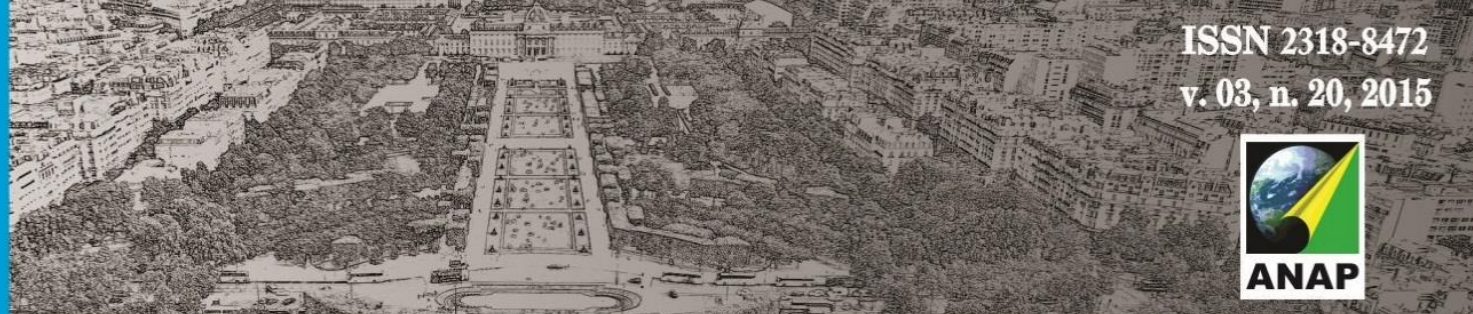

\section{Revista Nacional de}

Gerenciamento de Cidades

acessível); área de alimentação (71\% acessível); circulação externa (64\% acessível); parques Infantis I, II e III (respectivamente, 71\%, 12,5\%, 12,5\% acessíveis); e piscina (25\% de acessível). Na sequência são apresentados os principais problemas de cada ambiente analisado.

Acesso à Escola - na entrada principal não foi identificada qualquer barreira arquitetônica que pudesse comprometer a acessibilidade de alunos (Figura 4).

Acesso aos Edifícios - Com relação ao acesso ao prédio principal, dos itens avaliados, somente $\mathrm{o}$ item proteção da porta foi considerado fora dos padrões mínimos de acessibilidade.

Área Administrativa - Nos ambientes destinados a direção da escola e secretaria e a sala de professores, a avaliação identificou os seguintes problemas: a ausência de proteção na parte inferior das portas e disposição do mobiliário. No hall de entrada a estes ambientes não foi encontrado qualquer problema de acessibilidade espacial.

Área Pedagógica - Neste item os ambientes avaliados foram as duas salas de aula, berçário, sala de descanso e os sanitários masculino e feminino (Figuras 5 e 6). Dos elementos que comprometem a acessibilidade destacamos os seguintes problemas: a ausência de proteção nas portas e desnível na soleira das salas. Com relação aos sanitários masculino e feminino, a maioria dos indicadores analisados não foi considerado acessível. Dentre os problemas destacam-se: ausência de proteção na porta; ausência de barras de apoio no lavatório, próximo ao vaso sanitário e na área de banho e na área do trocador; tamanho do boxe do vaso sanitário; ausência de área de transferência no vaso sanitário; ausência de vaso sanitário elevado. 


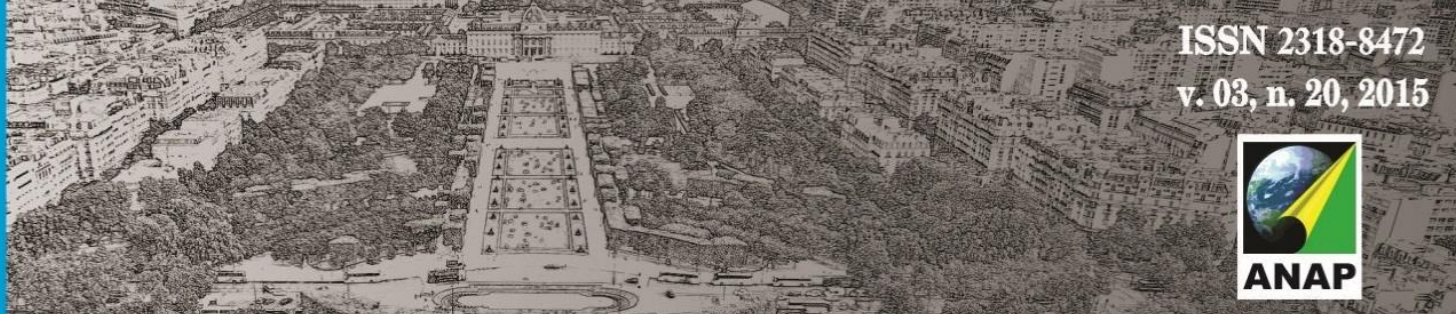

Revista Nacional de

Gerenciamento de Cidades

Figura 4 - Entrada principal

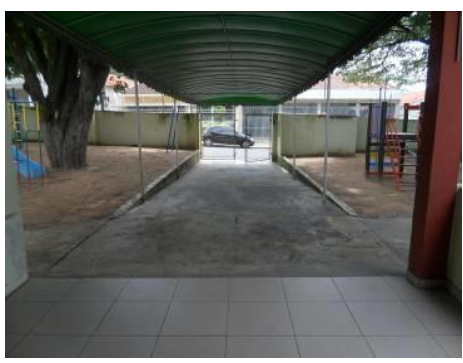

Figura 7 - Refeitório

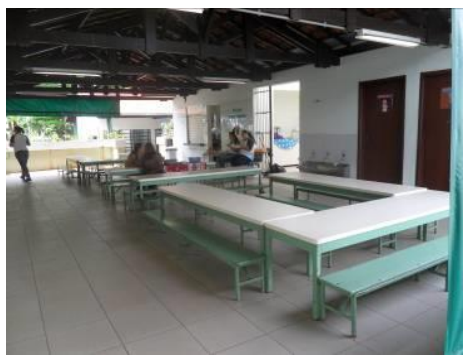

Figura 5 - Sala de Aula

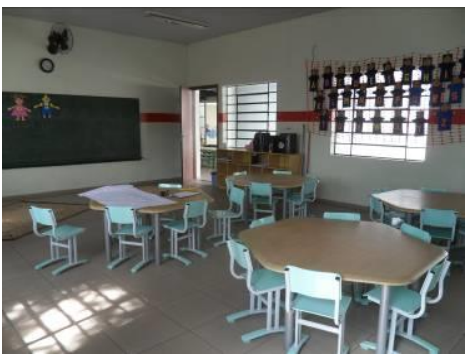

Figura 8 - Bebedouro

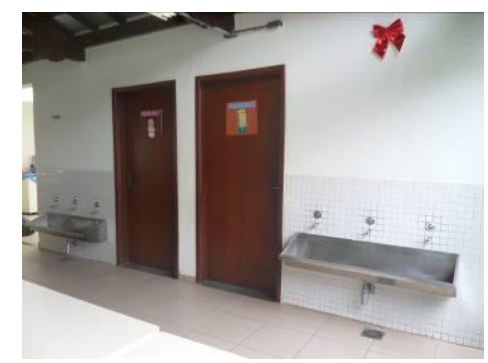

Figura 6 - Sala de Aula

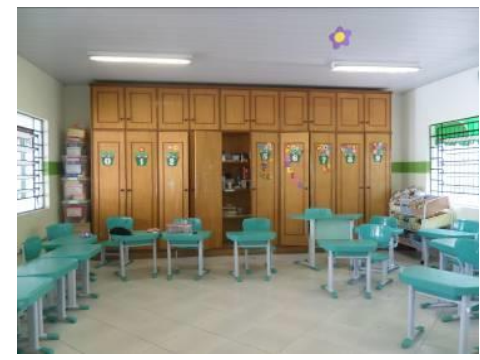

Figura 9 - Circulação

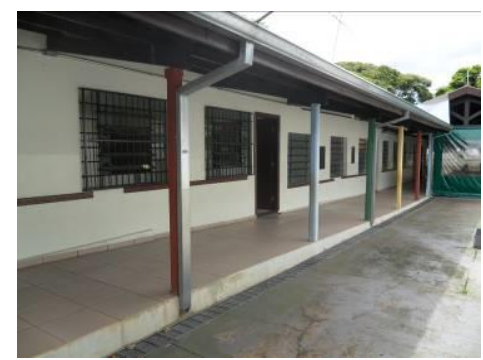

Área de Alimentação - Este ambiente é compreendido pelas áreas de refeição e área de bebedouro (Figuras 7 e 8). Neste espaço os elementos que não estão de acordo com a NBR 9050 foram: a altura das mesas é única, não possibilitando que a cadeira de rodas se acople a mesa; altura do bebedouro; ausência de barras de apoio e acionamento de água em uma única altura.

Circulação externa - Neste item foram avaliados os seguintes espaços: corredores - áreas externas, rampas e escadas (Figuras 9, 10, 11 e 12). Os corredores externos possuem largura e piso adequados; os problemas encontrados nestes espaços referem-se ao desnível entre estes espaços e os espaços contíguos (Figura 9) e o espaçamento das grelhas de coleta de água de chuva que pode comprometer o deslocamento da cadeira de rodas. Em relação às rampas de acesso à entrada da escola e à área administrativa, o único elemento ausente foi a presença de corrimão em duas alturas, conforme determina a NBR 9050. Com relação as escadas, constatou-se que uma das escadas que dá acesso ao refeitório altura do espelho variável entre $0,10 \mathrm{~m}$ a $0,17 \mathrm{~m}$ em desacordo com a NBR 9050. E em todas as escadas foi verificada ausência de corrimão em duas alturas, comprometendo o 


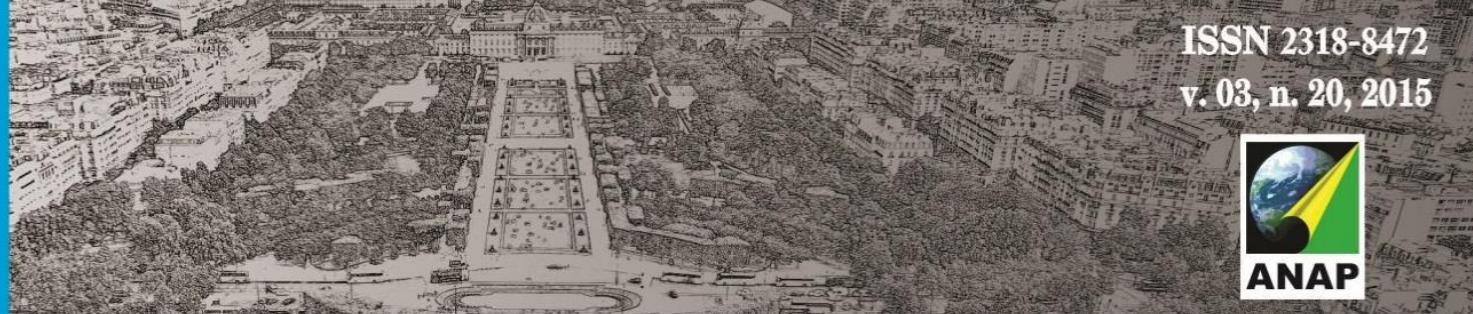

\section{Revista Nacional de}

Gerenciamento de Cidades

deslocamento dos alunos e docentes (Figuras 11 e 12).

Parque Infantil I - A área destinada ao Parque Infantil I é constituída por uma grande área livre, onde estão dispostos conjuntos de brinquedos para crianças pequenas (Figura 13). O piso desta área é de cimento desempenado. Com relação a acessibilidade foi identificada a presença de desníveis (degraus) para acessar o local. Os brinquedos mais próximos podem comprometer a segurança das crianças, podendo ser realocados com facilidade. Com relação à acessibilidade dos brinquedos, estes não possuem áreas de transferência para alunos com deficiência física, ou qualquer outro tipo de adaptação.

Parque Infantil II - Este parque está inserido em duas áreas contíguas separadas pela rampa de entrada na EMEI com gradis de aço tubular e tela de aço galvanizado (Figuras 14 e 15). A conexão destas áreas é realizada por uma circulação lateral entre estes espaços. O piso destas áreas é de terra (areia) e não há rotas para deslocamento de usuários de cadeiras de rodas; o que torna este espaço interno inadequado para o deslocamento de alunos deficientes físicos. A distância entre os brinquedos pode ser considerada segura; no entanto não foi constatada a presença de brinquedos que possam ser utilizados por alunos cadeirantes ou portadores de qualquer outra deficiência. Com relação aos balanços estes não possuem proteção da coluna. Este ambiente não foi considerado acessível, pois não permite a inclusão de alunos deficientes físicos nas atividades pedagógicas realizadas ao ar livre. 


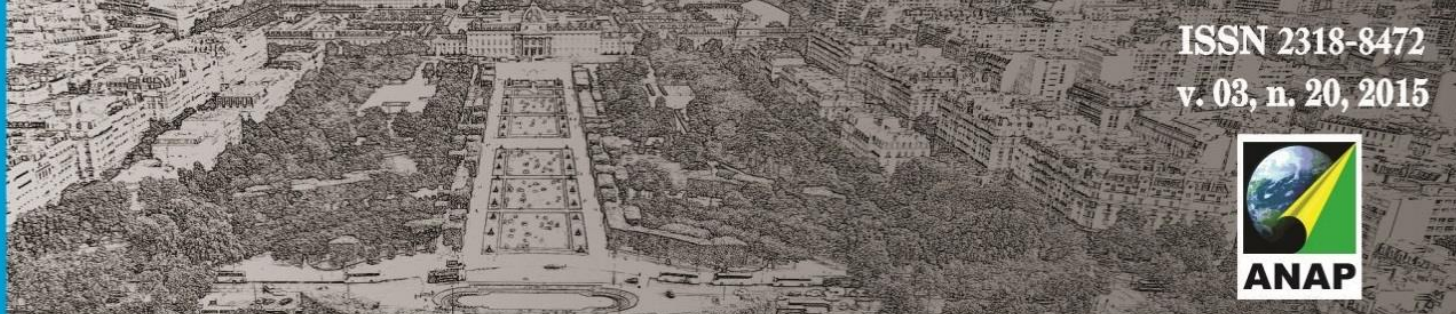

Revista Nacional de

Gerenciamento de Cidades

\section{- Análise da planta humanizada}

A análise da planta da EMEI Lions Club com relação às áreas livres, internas e externas, destinadas a circulação de usuários de cadeiras de rodas. Foi adotada como referência a medida de 0,90m, definida pela NBR 9050 (2004). A disposição dos mobiliários na planta foi inserida de acordo com o arranjo atual da escola. Os percursos traçados devem permitir o livre acesso do usuário no desempenho das atividades diárias em uma escola, ou seja, acessar as atividades pedagógicas (salas de aula, berçário, parque infantil) e demais atividades complementares, tais como: acessar os sanitários, o refeitório, sala da direção. Estes trajetos permitem que o aluno possa percorrer os ambientes, alcançar os mobiliários, equipamentos e outros elementos que compõem o seu dia a dia.

A Figura 19 apresenta os trajetos utilizados para a avaliação da acessibilidade espacial no interior dos ambientes e nas áreas externas da escola. Utilizou como referência para análise dos deslocamentos considerados acessíveis a cor verde, os deslocamentos com pouca acessibilidade ou com acessibilidade limitada, a cor laranja e os trajetos não acessíveis (em vermelho).

Figura 19 - Planta com layout e área livre de circulação para os usuários de cadeira de rodas.

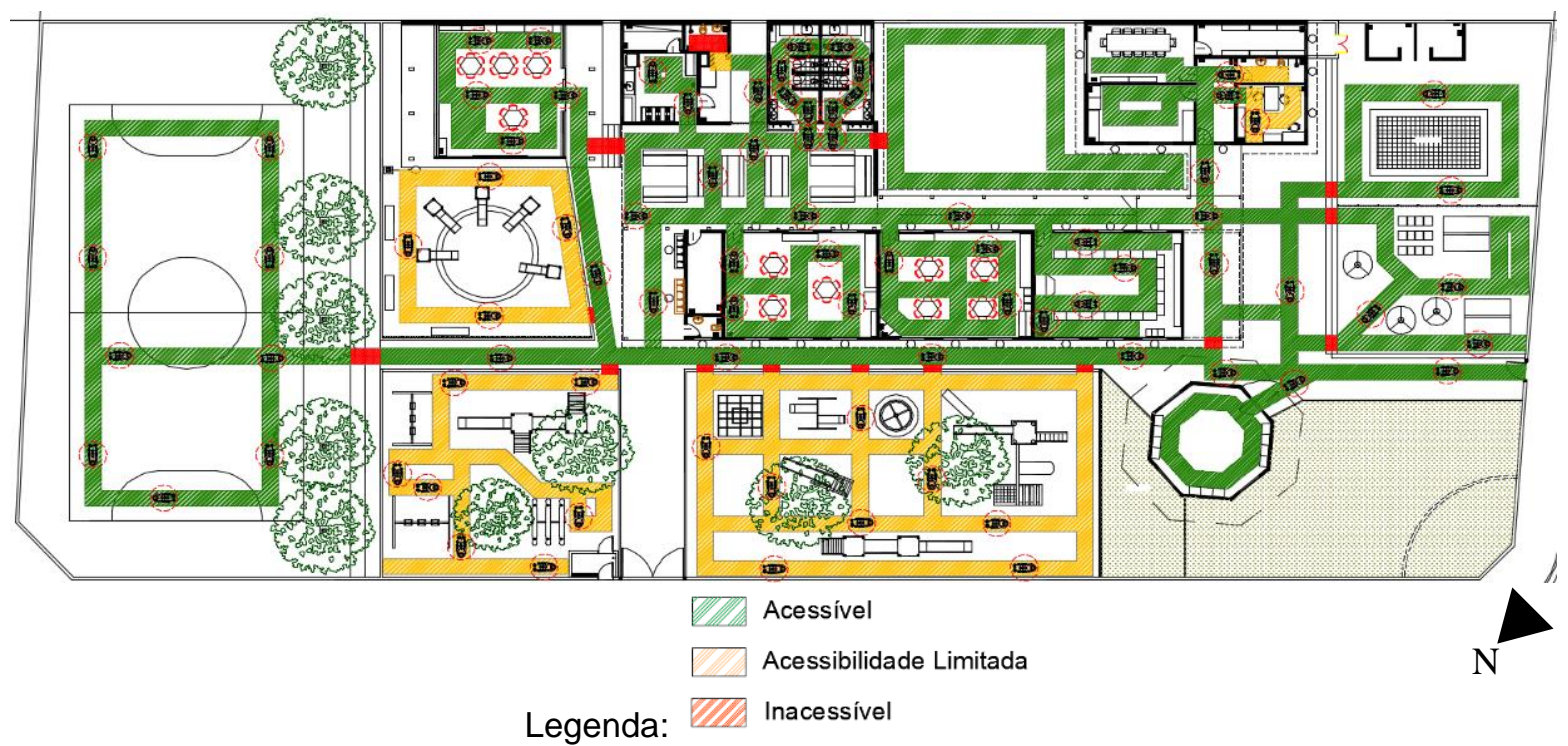

Fonte: Adaptado do projeto original, 2014. 
Revista Nacional de

Gerenciamento de Cidades

Ao analisar os deslocamentos lineares observou-se que tanto nas áreas administrativas quanto nas áreas pedagógicas, em função da disposição interna do mobiliário, e a dimensão das portas pode-se considerar estes espaços como acessíveis. $O$ único espaço interno considerado com acessibilidade limitada refere-se: i) ao acesso a sala da direção, pois o tamanho das mesas compromete o acesso de um aluno usuário de cadeira de rodas.

Com relação ao acesso aos parques infantis; no Parque Infantil I, apesar de haver espaço para a circulação de cadeiras de rodas e do piso concreto, existem degraus, para seu acesso. Para o Parque Infantil II, também há espaço adequado para a circulação de cadeiras rodas, no entanto, a existência de um "cordonel" de alvenaria, para contensão da terra (areia) e o próprio tipo de piso dificulta o acesso com cadeiras de rodas. Quanto o Parque Infantil III, há o "cordonel" de limitação do piso em areia grossa. $\mathrm{O}$ tipo de piso (terra compactada ou areia) encontrado nos parques infantis contribui para estes ambientes serem considerados com acessibilidade limitada ao usuário de cadeira de rodas. Seria adequado construir alguns trajetos construídos em um material mais adequado aos portadores de deficiência física. A ausência de brinquedos adaptados limita tanto a interação da criança deficiente com os demais alunos, quanto o seu desenvolvimento físico e psíquico. Os brinquedos devem propiciar as atividades psicomotoras da criança como andar, girar, subir, etc. Em relação à piscina a presença de escada e uma mureta e a ausência de um revestimento mais adequado tornam esse equipamento não acessível (Figuras 17 e 19).

$\mathrm{Na}$ sequência foi verificado se os ambientes internos permitem que seja realizada a manobra da cadeira de rodas em $180^{\circ}$ ou $360^{\circ}$ (Figura 19). Ao analisar os ambientes pode observar que os dois únicos espaços que comprometem este deslocamento referem-se: a sala da direção (em função do layout dos móveis) e os sanitários dos alunos (em função de suas dimensões internas).

As áreas destinadas aos sanitários podem ser consideradas os pontos mais problemáticos desta escola, pois não permite um reposicionamento de mobiliário, sem que seja realizada uma reforma total destes ambientes. 


\section{Revista Nacional de}

Gerenciamento de Cidades

Diante dos resultados apresentados é possível afirmar que as duas técnicas utilizadas foram complementares, e puderam comprovar que a maioria dos ambientes da EMEI Lions Club contribui parcialmente para a inclusão do aluno usuário de cadeira de rodas.

\section{CONCLUSÃO}

Este artigo teve como objetivo verificar o grau de inclusão escolar para alunos com deficiência motora, na EMEI Lions Club do município de Bauru. Os resultados apontaram que embora a legislação educacional e as normas de acessibilidade vigentes no país incentivem a promoção da inclusão de alunos deficientes nas escolas regulares; as unidades de ensino infantil ainda carecem de projetos ou reformas que eliminem as barreiras arquitetônicas existentes.

Dentre os espaços ou ambientes que mais chamaram a atenção durante a avaliação referiu-se a falta de acessibilidade nos sanitários infantis e nos parques infantis. Estes ambientes precisam ser reformados para que possam aumentar a acessibilidade da escola e uso pleno por seus usuários, principalmente daqueles com deficiência física.

Como desdobramento desta pesquisa, está em fase de estudo um aprofundamento do elenco de elementos que devem ser utilizados para avaliação da acessibilidade espacial em escolas infantis e um estudo da definição parâmetros que possam medir o grau de acessibilidade nas escolas infantis de Bauru.

Espera-se que as análises realizadas, possam auxiliar a direção da escola e os decisores municipais na redefinição de parâmetros e critérios, capazes de definir o grau de acessibilidade nas escolas infantis e assim estabelecer um planejamento de reforma para a eliminação de barreiras arquitetônicas nas escolas de ensino infantil no município de Bauru.

\section{REFERENCIAS}


Revista Nacional de

Gerenciamento de Cidades

ADA. The Americans with disabilities act. Checklist for readily achievable barrier removal. 1995. Disponível em: <http://www.usdoj.gov/crt/ada/checkweb.htm>. Acesso em janeiro, 2015.

ABATE, Tânia Pietzschze. Instrumentos de avaliação Pós-Ocupação (APO) adaptados a préescolas com deficiência física, auditiva e visual. Tese (Doutorado). Pós-Graduação em Arquitetura e Urbanismo. Universidade de São Paulo, São Paulo, 2011.

ASSOCIAÇÃO BRASILEIRA DE NORMAS TÉCNICAS. NBR 9050: Acessibilidade de pessoas portadoras de deficiência a edificações, espaço, mobiliário e equipamentos urbanos. Rio de Janeiro: ABNT, 2004.

BENVEGNÚ, Eliane M. Acessibilidade espacial requisito para uma escola inclusiva. Dissertação (Mestrado). Escolas Municipais de Florianópolis. Florianópolis, 2009.

BRASIL. Lei Federal 12.796/2013. Altera a Lei no 9.394, de 20 de dezembro de 1996, que estabelece as diretrizes e bases da educação nacional, para dispor sobre a formação dos profissionais da educação e dar outras providências. Ministério da Educação. 2013.

BRASIL. Ministério da Educação. Secretaria de Educação Básica. Parâmetros básicos de infraestrutura para instituições de educação infantil. Brasília: MEC, SEB, 2006.

CARVALHO, Telma Cristina Pichioli de. Arquitetura escolar inclusiva: construindo espaços para educação infantil. Tese (Doutorado). EESC/USP. 2008.

CORRÊA, Priscila Moreira. Elaboração de um protocolo para avaliação de acessibilidade física em escolas da educação infantil. Dissertação (Mestrado). UNESP. Marília, 2010.

DISCHINGER, Marta; BINS ELY; Vera Helena Moro; BORGES, Monna Michelle Faleiros da Cunha. Manual de acessibilidade espacial para escolas: o direito à escola acessível. Brasília: Ministério da Educação, Secretaria de Educação Especial, 2009.

DUARTE, Cristiane Rose de Siqueira; COHEN, R. Proposta de Metodologia de Avaliação da Acessibilidade aos Espaços de Ensino Fundamental. In: Anais NUTAU 2006: Demandas Sociais, Inovações Tecnológicas e a Cidade. São Paulo, USP: 2006.

ELALI, Gleice Azambuja. Ambientes para educação infantil, um quebra-cabeça? Contribuição metodológica na avaliação pós-ocupação de edificações e na elaboração de diretrizes para projetos arquitetônicos na área. Tese (Doutorado). Universidade de São Paulo. São Paulo, 2002

EVANGELISTA, Marta Maria Toledo Teixeira. A Construção do Projeto Político-Pedagógico na Escola Municipal de Educação Infantil (Emei) "Florípes Silveira de Souza". Dissertação (Mestrado). Programa de Pós-Graduação em Educação, da Faculdade de Filosofia e Ciências da UNESP - Campus de Marília. 2007.

FRANÇA, Ana Juditi Galbiatti Limongi. Ambientes contemporâneos para o ensino-aprendizagem: Avaliação pós-ocupação em três edifícios escolares públicos, situados na região metropolitana de São Paulo. Dissertação (Mestrado). FAU USP. 2011.

LOCH, Marcia do Valle Pereira. Convergência entre acessibilidade espacial escolar, pedagogia e escola Inclusiva. Tese (Doutorado). UFSC. Florianópolis. 2007. 
